\section{Neurophysiological Perspectives of Borderline Personality Disorders}

\section{Abstract}

Borderline Personality Disorder is a psychiatric disorder with complex underlying neurophysiology. Reviewing various literatures we came to understand that BPD is characterized by impulsive, aggressive, suicidal, self-inflicted harmful behaviors. Even though conventional theories ascribe to environmental etiologies (negative events such as childhood abuse and trauma). Genetic vulnerability disposes as one of the main factors which alter the neurophysiology of BPD patients. There is highly supportive evidence regarding the abnormalities of frontolimbic neuronal information processing, low cerebral serotonin states owing to dysfunction of serotonin genes, autonomic dysregulation in the context of poly vagal theory and cortical inhibition deficiency contributing towards symptomology and behavioral patterns of BPD patients.

Keywords: Borderline personality disorder; Neurophysiology; Neuronal processing; Behavior patterns

Received: March 22, 2017; Accepted: April 24, 2017; Published: May 05, 2017
Disruption of emotional regulation circuitry in Borderline Personality Disorder (BPD) is based upon on the effect of neurotransmitters caused by hypersensitivity to genetic and environmental factors. Researchers have based their studies largely on autonomic variations and negative reward systems.

\section{Review of Evidence}

According to current literature, BPD even though frequently begins during adolescence, the severity of symptoms show peak levels during young adulthood and decline gradually but progressively over the years [1]. BPD manifests in different ways but core features of it are rapidly changing moods, impulsitivity, auto aggressive behavior together with instability of interpersonal relationships and self-image [2]. The increase in understanding of mechanism of emotional dysfunction of BPD has led to various hypothesis but most profound ones are based on brain dysfunction linked to dual frontolimbic pathology mainly focusing on the alterations of brain regions involved in emotional processing such as hippocampus, amygdala, insula and prefrontal cortex. Several authors and previous studies have reported evidence to confirm this hypothesis as BPD patients demonstrated decrease in frontal lobe volume, loss of volume of hippocampus and amygdala as well as hyperactivity in anterior

\section{Introduction}

Marium Agha ${ }^{1}$, Areeba Nisar ${ }^{1}$, Hafsa Liaqat ${ }^{2}$, Usama Khalid Choudry ${ }^{3}$, Ammar Khalid Choudry' and Maria Shoaib ${ }^{4}$
Corresponding author:

Usama Khalid Choudry

\section{” ukchoudry@hotmail.com}

Department of Post Graduate Medical Education, Aga Khan University Hospital, Karachi, Pakistan.

Tel: +923456165524

Citation: Agha M, Nisar A, Liaqat $\mathrm{H}$, et al. Neurophysiological Perspectives of Borderline Personality Disorders. Acta Psychopathol. 2017, 3:3. cingulated cortex area and impulsitivity and suicidal behavior are implicated to prefrontal lobe areas [3]. A meta-analysis by Ruocco et al., integrated studies involving 205 BPD patients presented an average decrease of $11 \%$ in the size of the hippocampus and of $13 \%$ in the size of the amygdala [4] whereas, another one revealed reduction in hippocampus more prominent in BPD patients with PTSD in comparison with without PTSD who demonstrated volume reduction in right hippocampus was seen [5].

Another hypothesis is that BPD patients display cortical inhibition deficiency or increased cortical excitation indicated by short interval intra-cortical inhibition especially in BPD patients who have Attention Deficit Hyperactivity Disorder [6].

Another study links dysfunction in serotonin system in prefrontal cortex and anterior cingulated cortex to aggression, affective instability and self-destructive thoughts $[7,8]$. This study supports 
hypothesis mentioned above about the correlation between BPD patients and cortical inhibition deficiency as it occurs due to reduced capacity of corticostriatal pathway to synthesize serotonin [9] while also establishing importance of serotonin genes which predispose towards development of impulsive behavior as lower levels of CSF 5-HIAA exist in BPD patients who have previously attempted suicide [10]. Also BPD patients showed less sharp prolactin levels in response to fenfluramine (serotonin reuptake inhibitor) [11] suggesting decreased central 5-HT activity directly related to aggression and these patients also showed variations in platelet inhibition binding sites inversely proportional to self-mutilation behavior $[8,12]$. However another study while conducting the same fenfluramine challenge test found that there was decline in prolactin levels as opposed to blunt levels while also suggesting evidence of serotonin dysfunction in BPD patients but these results implied towards gender disposition as these findings were more significant in males as compared to females. A case control study was conducted comprising of 113 participants compared BPD with normal healthy individuals as control. From the 27 polymorphic markers in 7 genes selected it was genotypically analyzed that 5-HT2C, TPH2 rs10784941 and $r s 2171363$ were most notably related to BPD $(p=0.028$, $0.016,0.0005)$. These studies establish that central 5-HT function is inversely related to aggression, suicidal and impulsive behavior as reduced cerebrospinal fluid concentration of 5-HIAA metabolite plus lowered neuroendocrinological response to serotonergic agonists were observed through neuroimaging in studies done on 8 BPD patients $[13,14]$. Other neuropeptides such as oxytocin, vasopressin and opioids may also be altered in BPD patients as they play important role in the regulation of these affiliative behaviors [15]. Early traumatic experiences have impact on oxytocin as it is related to attachment and pro-social behavior [16] in addition to being modulated during stressful conditions as they heighten emotional stimuli in amygdala [17] which was significantly found in females, thus highlighting the negative effect of early traumatic experiences as pointed out by the studies carried out $[18,19]$.

In BPD patients emotional instability leads to dysfunction in endogenous opioid system as there is higher sensitivity to pain with lower levels of CSF- $\beta$-endorphin and met-encephalin specifically in BPD with Non-suicidal self-injurious behavior then in BPD patients with suicidal self-injurious behavior [20] this is triggered by extreme stress, dread of abandonment, unsafe sexual encounters and attention seeking behavior plus selfharming, anorexia, substance abuse these symptoms of BPD enhance regional $\mu$-opioid receptor availability [21] bilaterally in the orbitofrontal cortex, caudate, nucleus accumbens and left amygdala but lesser $\mu$-opioid receptor availability in the posterior thalamus; whereas during emotional stimulation for example in response to sadness, they exhibited more activation of the endogenous opioid system in the pregenual anterior cingulate, left orbitofrontal cortex, left ventral pallidum, left amygdala, and left inferior temporal cortex [22,23].

The main hypothesis which has been the focal point of recent studies and research is abnormalities in autonomic nervous system which has been expanded through Porges' Polyvagal theory and how it affects or attenuates some of the symptoms experienced by BPD patients. Vagal activity is involved in social response as it coordinates verbal communication and facial expression as well as communicating emotional states to others but during stressful and threatening situations there is a decrease in vagal tone which leads to decrease in parasympathetic activity and increase in sympathetic activity eventually leading to disruption in emotional stability [24]. A study in a laboratory was conducted aimed at 5 min stressors during which participants both BPD and normal healthy individual were given stressful tasks during this time frame, it was observed in healthy individuals during $5 \mathrm{~min}$ stressor the was initially an increase in sympathetic activity but then there was a decline in sympathetic activity while it remained increased in BPD patients due to inclination towards fight-orflight' response due to increased excitement [25].

Genetic disposition or genetic vulnerability has been observed in BPD patients this concept is based through gene-environment and genes physiologically responsible for stress in hypothalamicadrenal axis. As there is still development going on into building this notion few studies have been able to support it. One study used paradigm shift termed as plastic genes to identify genetic vulnerability in BPD patients. Familial and twin studies were used to estimate $40 \%$ heritability thus largely supporting the potential of genetic vulnerability as the root cause of BPD patients but even that susceptibility is based on negative events which trigger it like child hood abuse such as neglect, physical and sexual abuse as well [26]. While another study by extracting DNA sample from peripheral blood concluded correlation between NR3C1 methylation status and childhood maltreatment (specifically physical abuse) with clinical severity leading to imply that childhood trauma and BPD severity are related with higher NR3C1 methylation [27].

\section{Conclusion}

In this review we resolve that even though there is positive primary association of environmental adversity in BPD patients however there is growing evidence supporting genetic vulnerability as key to neurophysiology of BPD, therefore high risk groups should screened regularly for symptoms of the disease. While a number of hypothesizes have been proposed about the factors responsible for emotional dysregulation found in BPD patients, the ones which have the most ground and are evidently supported are abnormalities in frontolimbic structures, serotonin gene dysfunction and autonomic system dysregulation based on polyvagal theory. It may not be a farfetched approach to reduce the exposure to BPD patient to environments/ situations responsible for triggering serotonergic or cholinergic activity. Additionally, cognitive behavioral therapy for BPD can be reformed based on its neurophysiology. The understanding of the neurophysiology of BPD paves the way for having a better insight into disease manifestations and inculcates the road to improved patient management. 


\section{References}

1 Zanarini MC, Frankenburg FR, Hennen J, Reich DB, Silk KR (2005) The McLean study of adult development (MSAD): overview and implications of the first six years of prospective follow-up. J Pers Disord 19: 505-552.

2 American Psychiatric Association (1994) Diagnostic and Statistical Manual of Mental Disorders-DSM-IV. Wash ington, DC: American Psychiatric Association.

3 Lyoo IK, Han MH, Cho DY (1998) A brain MRI study in subjects with borderline personality disorder. J Affect Disord 50: 235-243.

4 Ruocco AC, Amirthavasagam S, Zakzanis KK (2012) Amygdala and hippocampal volume reductions as candidate endophenotypes for borderline personality disorder: a meta-analysis of magnetic resonance imaging studies. Psychiatry Res 201: 245-252.

5 Rodrigues E, Wenzel A, Ribeiro MP, Quarantini LC, Miranda-Scippa A, et al. (2011) Hippocampal volume in borderline personality disorder with and without comorbid posttraumatic stress disorder: a metaanalysis. Eur Psychiatry 26: 452-456.

6 Moll GH, Heinrich H, Rothenberger A (2003) Methylphenidate and intracortical excitability: Opposite effects in healthy subjects and attention-deficit hyperactivity disorder. Acta Psychiatr Scand 107: 69-72.

7 Audenaert K, Peremans K, Goethals I, Otte A, Dierckx R, et al. (2005) Functional imaging of the suicidal brain. Nucl Med Commun 26: 391393.

8 Schmahl C, Bremner JD (2006) Neuroimaging in borderline personality disorder. J Psychiatry Res 40: 419-427.

9 Leyton M, Okazawa H, Diksic M, Paris J, Rosa P, et al. (2001) Brain Regional alpha-[11C] methyl-L-tryptophan trapping in impulsive subjects with borderline personality disorder. Am J Psychiatry 158: 775-782.

10 Gardner DL, Lucas PB, Cowdry RW (1990) CSF metabolites in borderline personality disorder compared with normal controls. Biol Psychiatry 28: 247-254.

11 Hansenne M, Pitchot W, Pinto E, Reggers J, Scantamburlo G, et al. (2002) 5-HT1A dysfunction in borderline personality disorder. Psychol Med 32: 935-941.

12 Simeon D, Stanley B, Frances A, Mann JJ, Winchel R, et al. (1992) Self-mutilation in personality disorders: psychological and biological correlates. Am J Psychiatry 149: 221-226

13 Coccaro EF, Siever L, Klar HM, Maurer G, Cochrane K, et al. (1989) Serotonergic studies in patients with affective and personality disorders. Correlates with suicidal and impulsive aggressive behavior. Arch Gen Psychiatry 46: 587-599.

14 Herpertz S, Sass H, Favazza A (1997) Impulsivity in self-mutilative behavior: psychometric and biological findings. J Psychiatr Res 31: 451-465.

15 Insel T (2003) Is social attachment an addictive disorder? Physiol Behav 79: 351-357.

16 Meyer-Lindenberg A, Domes G, Kirsch P, Heinrichs M (2011) Oxytocin and vasopressin in the human brain: social neuropeptides for translational medicine. Nat Rev Neurosci 12: 524-538.

17 Heinrichs M, von Dawans B, Domes G (2009) Oxytocin, vasopressin, and human social behavior. Front Neuroendocrinol 30: 548-557.

18 Kirsch P, Esslinger C, Chen Q, Mier D, Lis S, et al. (2005) Oxytocin modulates neural circuitry for social cognition and fear in humans. $J$ Neurosci 25: 11489-11493.

19 Bartz J, Simeon D, Hamilton H, Kim S, Crystal S, et al. (2011) Oxytocin can hinder trust and cooperation in borderline personality disorder. Soc Cogn Affect Neurosci 6: 556-563.

20 Stanley B, Siever LJ (2010) The interpersonal dimension of borderline personality disorder: toward a neuropeptide model. Am J Psychiatry 167: 24-39.

21 Bandelow B, Schmahl C, Falkai P, Wedekind D (2010) Borderline personality disorder: a dysregulation of the endogenous opioid system? Psychol Rev 117: 623-636.

22 Stanley B, Sher L, Wilson S, Ekman R, Huang YY, et al. (2010) Nonsuicidal self-injurious behavior, endogenous opioids and monoamine neurotransmitters. J Affect Disord 124: 134-140.

23 Prossin AR, Love TM, Koeppe RA, Zubieta JK, Silk KR (2010) Dysregulation of regional endogenous opioid function in borderline personality disorder. Am J Psychiatry 167: 925-933.

24 Porges SW (2004) Neuroception: A subconscious system for detecting threat and Safety. Zero to Three: Bulletin of the National Center for Clinical Infant Programs 24: 19-24.

25 Porges SW (1995) Orienting in a defensive world: Mammalian modifications of our evolutionary heritage. A polyvagal theory. Psychophysiology 32: 301-318.

26 Amad A, Ramoz N, Thomas P, Jardri R, Gorwood P (2014) Genetics of borderline personality disorder: Systematic review and proposal of an integrative model. Neurosci Biobehav Rev 40: 6-19.

27 https://www.researchgate.net/journal/1559-2308_Epigenetics_ official_journal_of_the_DNA_Methylation_Society 7: 853-857 